\title{
Perancangan Sistem Informasi Pelayanan Pengobatan Pasien Umum Dan Bpjs Menggunakan Visual Basic Pada Klinik Batara Di Jalan Panglima Denai Kota Medan Provinsi Sumatera Utara Tahun 2019
}

\author{
Diah Indah Sari, Raudhatul Jannah, Ari Usman Caniago
}

Sistem Informasi, Universitas Islam Negeri Sumatera Utara

\begin{tabular}{l}
\hline \hline Article Info \\
\hline Article history: \\
Received Jun $12^{\text {th }}, 2020$ \\
Revised Aug $20^{\text {th }}, 2020$ \\
Accepted Aug $26^{\text {th }}, 2020$ \\
\\
Keyword: \\
Sistem Informasi, Registrsi \\
klinik, Visual Studio.
\end{tabular}

Article Info

ticle history:

Revised Aug 20 ${ }^{\text {th }}, 2020$

\begin{abstract}
sistem informasi sangat diperlukan di klinik agar dapat membantu dalam melakukan tugas-tugas administrasi klinik guna meningkatkan mutu pelayanan klinik yang melayani masyarakat di bidang kesehatan. Registrasi pasien di klinik merupakan salah satu komponen dalam sistem informasi yang sangat diperlukan karena pelayanan yang diberikan di klinik harus optimal dalam arti cepat dan tepat. Saat ini, sistem registrasi pasien yang dilakukan di klinik Batara masih dilakukan secara manual. Sehingga memiliki banyak kelemahan yang akan menurunkan mutu pelayanan kesehatan. Penelitian ini bertujuan untuk merancang sistem informasi registrasi pasien di klinik Batara agar mempermudah pendaftaran pasien yang sebelumnya dilakukan secara manual.Metode pengembangan sistem registrasi pasien ini dibuat dengan menggunakan metode siklus hidup pengembangan sistem atau System Development Life Cycle (SDLC). dan dirancang menggunakan perangkat lunak Microsoft Visual Studio. Metode tersebut meliputi beberapa tahapan proses yaitu tahap perencanaan sistem, tahap analisis sistem, tahap perancangan sistem, tahap penerapan sistem, tahap evaluasi sistem, tahap penggunaan dan pemeliharaan sistem. Hasil dari pengembangan sistem registrasi ini adalah sebuah perangkat lunak (software) yang dikembangkan menggunakan perancangan input, perancangan database dan perancangan output, yang berguna membantu petugas klinik dalam pencatatan data pasien. Berdasarkan hasil penelitian, diharapkan kepada klik Batara agar mempersiapkan sarana prasarana untuk mendukung berjalannya sistem ini, serta menerapkan perangkat lunak ini di bagian registrasi pasien agar mempermudah proses pendaftaran dan pembuatan laporan kunjungan pasien sehingga $\mathrm{m}$ enghasilkan informasi yang akurat.
\end{abstract}

Copyright (0) 2020 STMIK Triguna Dharma. All rights reserved.

\footnotetext{
First Author

Nama : Diah Indah Sari

Program Studi :Sistem Informasi

Universitas Islam Negeri Sumatera Utara

Email : diahindahsari1202@gmail.com
}

\section{PENDAHULUAN}

Perkembangan teknologi informasi telah mengubah manusia dalam menyelesaikan semua pekerjaannya, seperti pada saat pencarian informasi. Jika dahulu manusia mencari informasi sebatas pada media cetak, maupun secara lisan, sekarang lebih banyak mencari informasi melalui internet, secara tidak langsung dapat dikatakan semua serba terkomputerisasi. Sebagai bentuk nyata bahwa perkembangan teknologi informasi sangat diperlukan adalah adanya sistem informasi. Sistem informasi sangat membantu dan diperlukan untuk mempermudah tugas manusia, seperti di perusahaan, instansi, organisasi, maupun di berbagai bidang, serta dalam bidang pelayanan kesehatan seperti: klinik yaitu membantu dalam penanganan sistem pendaftaran 
pasien yang bertujuan untuk mempermudah melakukan tugas-tugas administrasi klinik dengan efektif dan efisien. (Sulaiman, 2011),

Klinik adalah fasilitas pelayanan kesehatan yang menyelanggarakan upaya kesehatan masyarakat. Klinik sebagai pusat pelayanan kesehatan yang merupakan salah satu instansi yang bergerak dibidang pelayanan jasa kesehatan perorangan dan masyarakat yang bertanggung jawab menyelenggarakan pelayanan kesehatan secara menyeluruh, terpadu, dan berkesinambungan. Sebagai pelayanan pendaftaran yang pertama kali diterima oleh pasien, maka mutu pelayanan dapat dinilai dari sini yakni mutu pelayanan pendaftaran yang meliputi kecepatan, kelengkapan, ketepatan, dan kejelasan informasi serta kenyamanan ruang tunggu dan lainnya (Sutabri, 2012). Pengolahan data pendaftaran pasien di klinik masih banyak dilakukan dengan cara manual meliputi kegiatan pencatatan data identitas pasien, pencarian data rekam medis pasien, pemberian kartu pasien maupun pembuatan laporan untuk mengetahui jumlah pengunjung puskesmas tersebut. Namun penelitian ini sering kali membutuhkan waktu yang lama dan pekerjaan yang rumit menghitung secara manual atau Microsoft Excel (Ariusman.dkk,2017)

Sehingga megakibatkan lamanya pelayanan pendaftaran pasien. Maka dengan adanya sistem informasi ini diharapkan hal yang demikian tidak terjadi lagi karena pencatatan dan pencarian data akan dilakukan secara cepat dengan komputer. Dari hasil observasi pada bulan januari 2019, diketahui bahwa sistem informasi di klinik Batara khususnya sistem informasi pendaftaran pasien masih dilakukan secara manual yaitu dengan mengisi data identitas pasien dengan media kertas. Pada kenyataannya sering kali terjadi kesalahan dalam pengisian data pasien, Maka sebab itu untuk meningkatakan mutu pelayanan kesehatan kepada masyarakat, perlu melakukan perancangan sistem informasi yang berkaitan dengan pengelolaan data dan informasi pasien khususnya pada sistem registrasi pasien agar dapat diselesaikan dengan lebih cepat dan akurat. Dengan menerapkan sistem informasi registrasi pasien di klinik batara di jalan panglima denai kota medan provinsi sumatera utara, diharapkan akan mempermudah petugas klinik dalam melaksanakan tugasnya dengan baik dan lancar guna meningkatkan pelayanan kesehatan kepada masyarakat yang berkunjung. (Sabarguna, B.S., 2008)

\section{METODE PENELITIAN}

Pengembangan sistem informasi registrasi klinik batara ini dibuat dengan mengggunakan metode daur pengembangan sistem informasi yang lebih umum dinamakan (System Development Life Cycle / SDLC) atau daur hidup pengembangan sistem. Metode ini mencakup sejumlah fase atau tahapan, yaitu fase perancanaan (Planning Phase), Fase Pengembangan (Inverstigasi, analisis, desain, implementasi). Menurut (Sutabri, 2012), Berikut ini adalah tahapan yang dilakukan dalam proses SDLC pada klinik batara :

\section{Perencanaan System}

Merupakan tahapan pengidentifikasian system informasi yang akan dikembangkan, hal-hal yang ingin di capai, jangka waktu,serta mempertimbankan dana dan orang yang melaksanakan. (Sabarguna, B.S., A. 2008).

\section{Analisis System}

Tahap ini merupakaqn tahapan menganalisis fasilitas apa saja yang di butuhkan dalam perancangan sebuah system. Yakni di antaranya : Kelayakan teknis terdiri atas : persiapan perangkat keras, persiapan perangkat lunak, Kelayakan operasional, Kelayakan ekonomis, Kelayakan hukum. (Kadir, 2003).

\section{Perancangan System}

a. Perancangan system secara umum

b. Perancangan system secara rinci

c. Perancangan input

d. Perancangan database

Database merupakan kumpulan dari data-data yang saling terkait satu dengan yang lainnya, digunakan perangkat lunak tertentu untuk memanipulasinya. (Wahana Komputer. 2005).

Database Pendaftaran

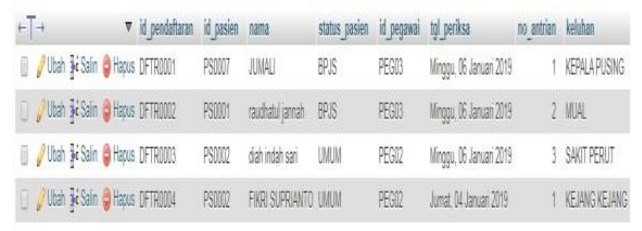

Gambar 1: Tampilan Database pendaftaran 
Database Pasien

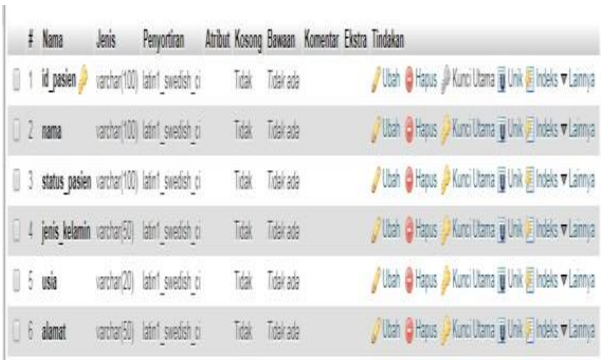

Gambar 2: Tampilan Database Pasien

Database Pegawai

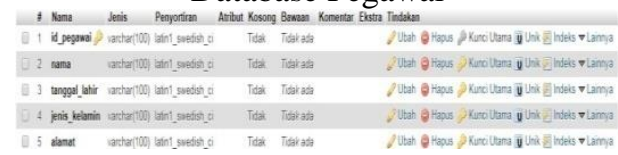

Gambar3: Tampilan Database Pegawai

Database Dokter

\begin{tabular}{|c|c|c|c|}
\hline i id dother ? & 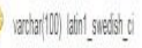 & 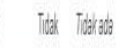 & 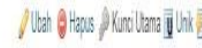 \\
\hline ? 2 and & 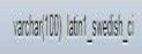 & Tiat Tistath & J that of \\
\hline tamgal. & 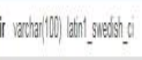 & 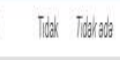 & 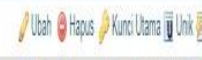 \\
\hline 4 jis telenin & 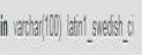 & Tidid Tibsesh & 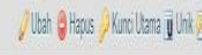 \\
\hline
\end{tabular}

Gambar4:Tampilan Database Dokter

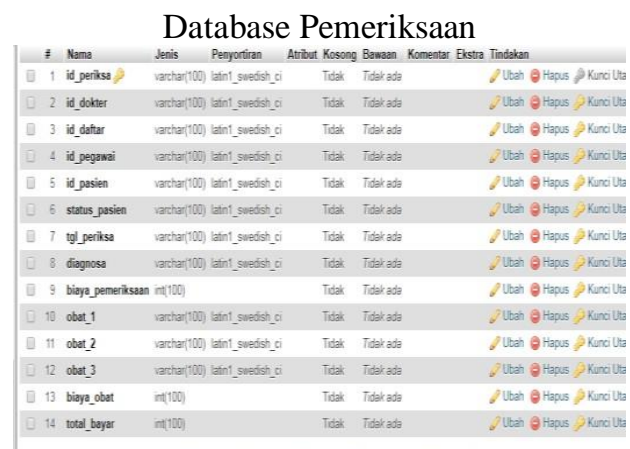

Gambar 5: Tampilan Databse Pemeriksaan

Database Penyakit

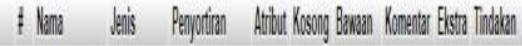

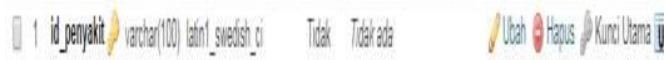

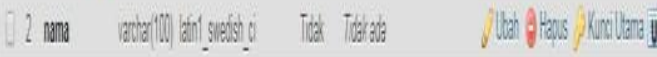

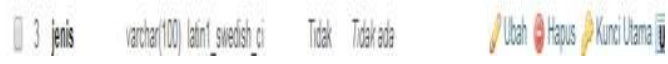

Gambar 6: Tampilan Database Penyakit 


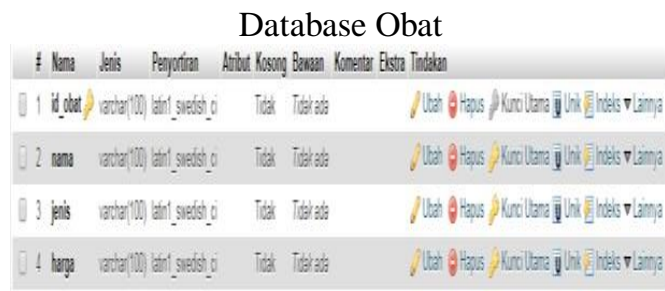

e. Penyimpanan dan Pengolahan Data

Gambar 7: Tampilan Database Obat

Setelah proses input dilakukan data akan tersimpan di database. Lalu pengolahan data mengunakan Visual Studio 2008 dan Crystal Reports 8.5 untuk membuat laporan. (Kadir, 2003).

f. Perancangan Output

Output (keluaran) adalah produk dari sistem informasi yang dapat dilihat oleh pemakainya. Output berisi informasi yang merupakan hasil pengolahan dari data yang ada dan berguna bagi pemakainya. Desain output pada program sistem registrasi pasien di klinik adalah dalam bentuk tabel yang berupa laporan berobat pasien. (Kadir, 2003).

\section{g. Implementasi system}

Pada tahap implementasi ini kegiatan yang dilakukan hanya uji coba sistem. Pengujian sistem dilakukan di dengan bantuan senior untuk menganalisis system yang telah dibuat. Sementara tahap instalasi perangkat keras dan perangkat lunak serta sosialisasi sistem tidak dilakukan karena untuk melalui setiap tahapannya akan membutuhkan waktu yang cukup lama. Oleh karena itu, pengembangan sistem ini hanya sampai di tahap uji coba. (Yakub, 2012).

3.

ANALISIS DAN HASIL

Flowchart Program (Adelia, J. 2011).

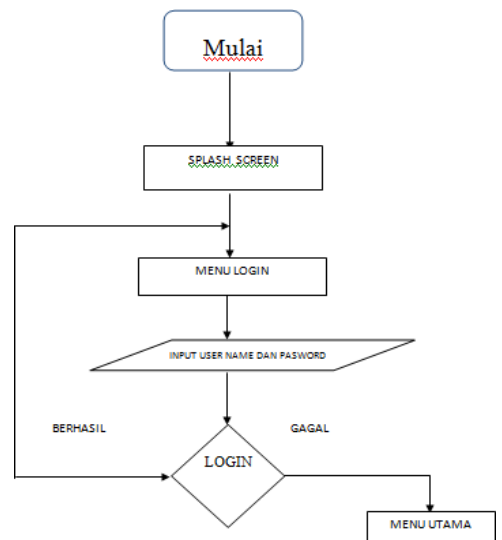

Gambar 8: Tampilan flowchart login

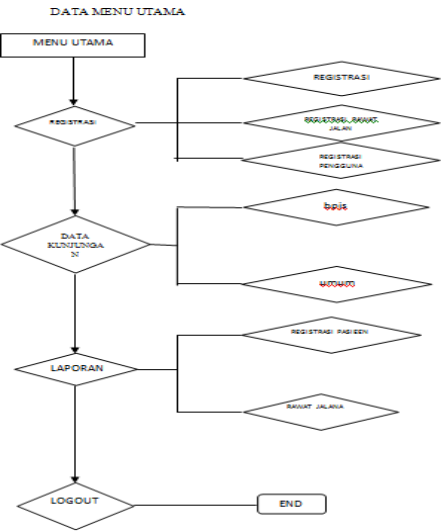

Gambar 9: Tampilan flowchart menu utama 


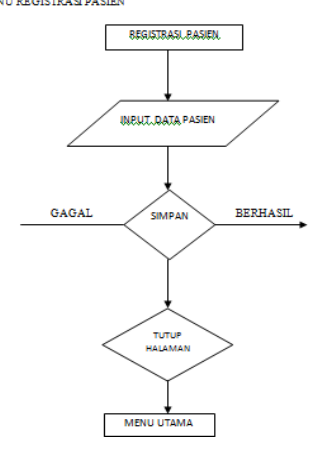

Gambar 10: Tampilan flowchart registrasi pasien

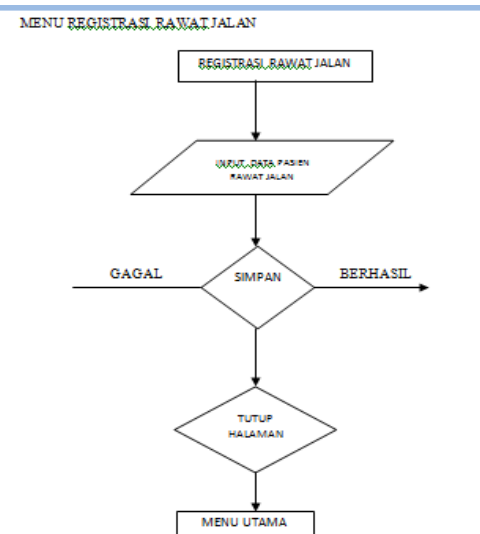

Gambar 11: Tampilan flowchart rawat jalan

NIENU REGISTRASI PENGGUNA

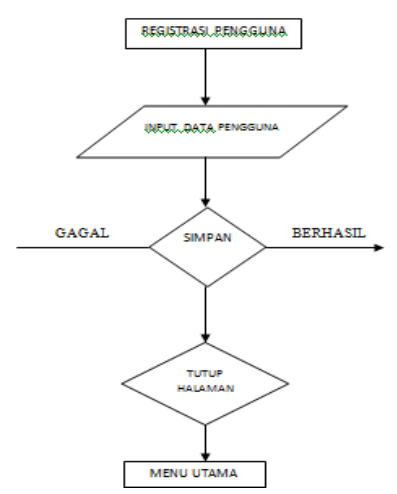

Gambar 12: Tampilan flowchart registrasi pengguna

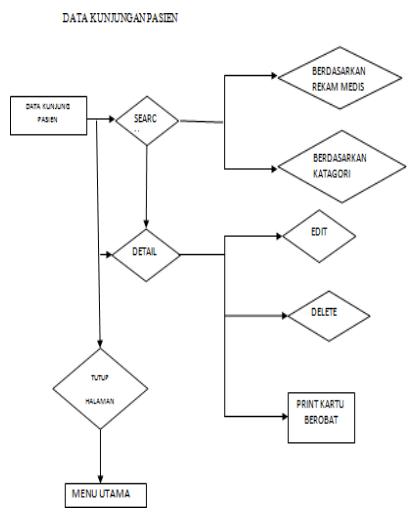

Gambar 13: Tampilan flowchart data kunjungan pasien 


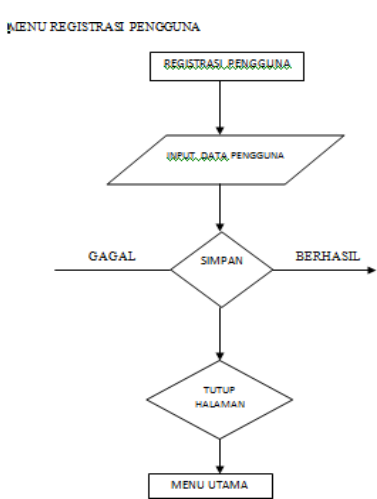

Gambar 14: Tampilan flowchart registrasi pengguna

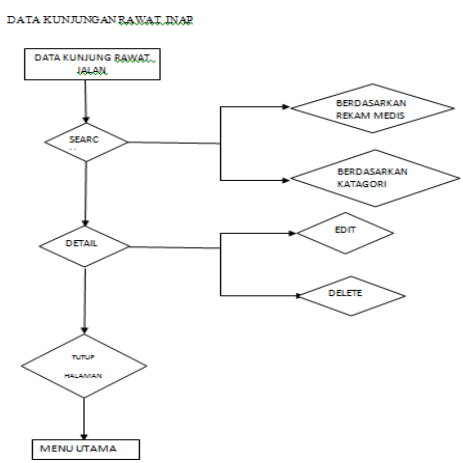

\section{Gambar 15: Tampilan flowchart kunjungan rawat inap}

$$
\text { MENULADORANREGSTRASPASIDV }
$$

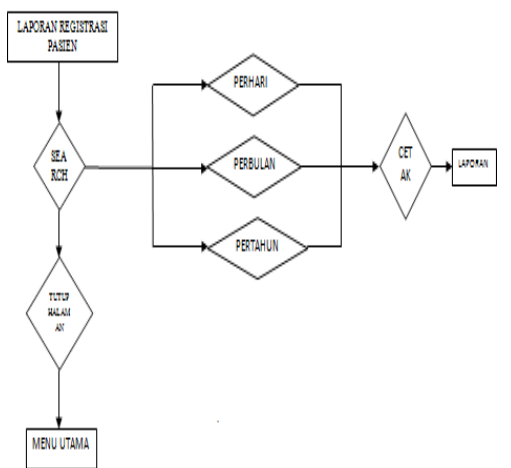

\section{Gambar 16: Tampilan flowchart menu laporan registrasi pasien}

\section{Keuntungan Sistem Registrasi Pasien}

Keuntungan menggunakan sistem registrasi pasien di diantaranya klinik batara di jalan panglima denai kota medan provinsi sumatera utara diantaranya.

- $\quad$ Kemudahan dalam meng-input data pasien

- $\quad$ Kemudahan dalam pembuatan kartu berobat pasien

- $\quad$ Kemudahan dalam pembuatan laporan kunjungan pasien

- $\quad$ Efisiensi Sumber Daya Manusia (SDM)

- Keamanan dataKeakuratan data

\section{Kekurangan Sistem Registrasi Pasien}

Kekurangan dalam menggunakan sistem registrasi pasien dengan menggunakan program komputer di klinik batara yaitu penggunaan sistem yang hanya dapat dilakukan pada satu komputer saja dan tidak dapat dilakukan secara online karena belum tersedianya LAN (Local Area Network). Sehingga berkas rekam medis pasien yang mendaftar harus dikirim ke poli tujuan pasien, dan dikembalikan setelah pasien selesai berobat atau pasien telah mendapat layanan di klinik batara.

4.

IMPLEMENTASI DAN UJI COBA 
- Form Login

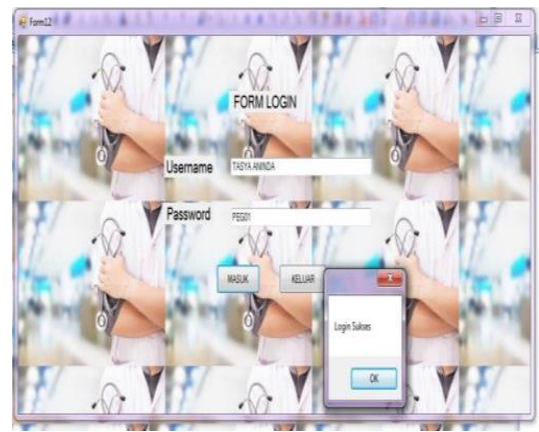

Gambar 17: Tampilan form login

- Menu Tampilan Pasien

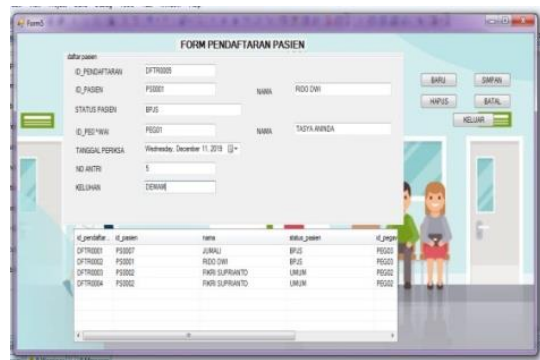

Gambar 18: Tampilan Menu Pendaftaran Pasien

- $\quad$ Registrasi Pegawai

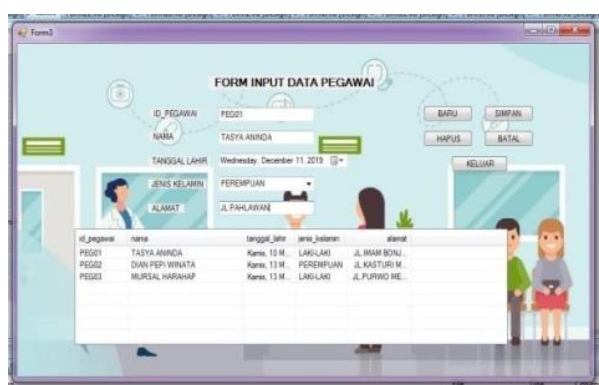

Gambar 19: Tampilan Regitrasi pegawai

- Form Dokter

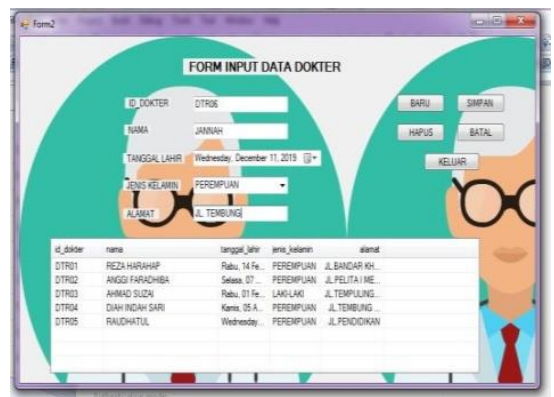

Gambar 20: Tampilan from dokter

- $\quad$ Form Periksa 


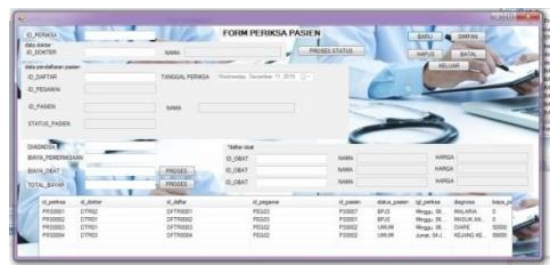

Gambar 21: Tampilan from periksa

- Cari Obat

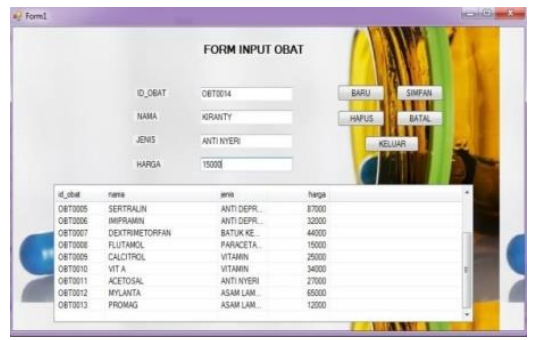

Gambar 22: Tampilan cari obat

- $\quad$ Laporan Harian

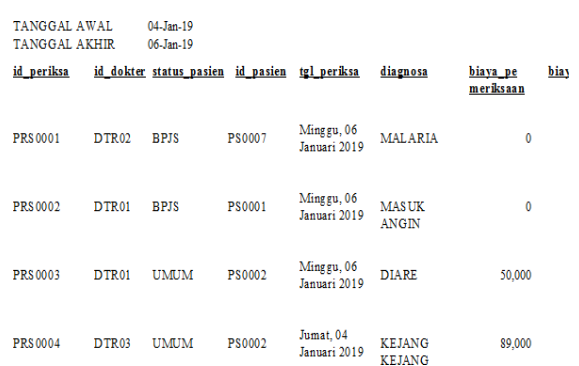

Gambar 23: Tampilan laporan harian

- $\quad$ Kartu Berobat

\begin{tabular}{|c|c|}
\hline \multicolumn{2}{|c|}{$\begin{array}{l}\text { KLINIK BATARA } \\
\text { IALAN PANGLIMA DENAI KOTA MEDAN PROVINSI } \\
\text { SUMAATERA UTARA TAHUN } 2019\end{array}$} \\
\hline & KARTU BEROBAT \\
\hline NO & $: 001$ \\
\hline NAMA PASIEI & $\mathrm{V}:$ JANNAH \\
\hline TGL LAHIR & : 16 JULI 1999 \\
\hline JENIS BAYAR & : BPJS \\
\hline
\end{tabular}

\section{Gämbar 24: Tampilan kartu Berobat}

5. KESIMPULAN

Pada sistem registrasi pasien di klinik batara yang telah dikembangkan yaitu:

- Tersedia form login

- form cari dokter,

- form input data dokter,

- form input data pegawai,

- form input data pasien,

- form pendaftaran pasien,

- form cari pasien, 
- form periksa pasien,

- form cari pendaftaran pasien,

- form cari obat,

- form input obat,

- laporan harian berobat.

\section{DAFTAR PUSTAKA}

- Adelia, J. (2011). Implementasi Customer Relationship Management (CRM) Pada Sistem Reservasi Hotel Berbasis Website Dan Desktop. Sistem Informasi , Vol. 6. No. 2, 113-126.

- Ariusman,Dkk. (2017). Rancangan Bangun Aplikasi Penetapan Dosis Obat Individual Menggunakan Pemprograman Visual Basic.Net Berdasarkan Perhitungan Farmakokinetik. Teknik Informatika. Vol.2.No.2 44-48.

- Sulaiman, E. (2011). Manajemen Kesehatan Teori Dan Praktik Di Puskesmas. Surakarta: Gajah Mada University Press.

- Sutabri, T. (2012). Analisis Sistem Informasi. Yogyakarta: CV. Andi Offset.

- Sabarguna, B.S., A. (2008). Sistem Informasi Klinis. Jakarta: UI Press.

- Wahana Komputer. (2005). Tutorial 5 Hari Menggunakan Microsoft Access 2003. Yogyakarta: CV. Andi Offset.

- Kadir, A. (2003). Pengenalan Sistem Informasi. Yogyakarta: CV. Andi Offset.

- Yakub. (2012). Pengantar Sistem Informasi. Yogyakarta: Graha Ilmu.

- Yuliana, O. (2007). Aplikasi Jitu Pembahasan Aplikasi Database Microsoft Access. Yogyakarta: Graha Ilmu. 